\title{
Classification of gallstones using Fourier-transform infrared spectroscopy and photography
}

\author{
Byeong Jo $\mathrm{Ha}^{1}$ and Sangsoo Park ${ }^{2^{*}}$ iD
}

\begin{abstract}
Background: Gallstones have conventionally been classified by gross inspection into 4 categories: cholesterol gallstones, black pigment (calcium bilirubinate) gallstones, brown gallstones, and mixed gallstones that contain both cholesterol and calcium bilirubinate. Classification using Fourier-transform infrared (FT-IR) spectroscopy supplements gross inspection; however, the issue of ambiguity in gallstone classification has not been fully addressed to date.

Methods: Twenty-six gallstones obtained after surgical gallbladder removal were examined using FT-IR spectroscopy and digital photography, and classified into 6 gallstone groups according to characteristic FT-IR absorption bands.

Results: FT-IR spectra of nine gallstones matched well with that of pure cholesterol, and the gallstones were thus classified as cholesterol stones. Twelve gallstones were classified as calcium bilirubinate stones as they showed characteristic absorption bands of calcium bilirubinate. However, the FT-IR spectra of these gallstones always showed a broad absorption band of bound water at $3600-2400 \mathrm{~cm}^{-1}$. The other five gallstones were classified as mixed stones with combinations of cholesterol, calcium bilirubinate, and calcium carbonate.

Conclusion: FT-IR spectroscopy is a powerful and convenient method for gallstone classification. Nevertheless, one should take serious note of the superposition of FT-IR absorption bands of different chemical components of gallstones including that of bound water.
\end{abstract}

Keywords: Gallstone composition, FT-IR spectroscopy, Cholesterol, Calcium bilirubinate, Calcium carbonate

\section{Background}

Gallstone formation in the gallbladder, bile duct, and liver is a common digestive disease, occurring in $10-20 \%$ of the population in Western countries, and approximately $25 \%$ of these patients eventually require surgical removal due to severe symptoms $[1,2]$. Traditionally, gallstones have been divided by gross inspection into 4 categories: cholesterol stones, black pigment (calcium bilirubinate) stones, brown color stones, and mixed stones that consist of both cholesterol and calcium bilirubinate [2-4]. However, this classification method is largely dependent upon the external shape and color of gallstones and does not accurately reflect the cases wherein the internal morphology of gallstones is different from the external one.

\footnotetext{
* Correspondence: spark@eulji.ac.kr

Department of Biomedical Engineering, College of Health Science, Eulji University, 553 Sanseongdae-ro, Sujeong-gu, Seongnam, Gyeonggi-do 13135, Republic of Korea

Full list of author information is available at the end of the article
}

Fourier-transform infrared (FT-IR) spectroscopy has been a major tool for gallstone classification and constituent analysis [5-13], as the technique is fast and applicable to all types of gallstones, irrespective of crystallinity, and requires only a small amount of sample. FT-IR is particularly useful when gallstone samples from a large number of patients are examined for purposes of classification and studying the etiology of gallstone formation [5-9]. It is now well established through these studies that cholesterol, calcium bilirubinate, and calcium carbonate are the three major constituents of gallstones. For detailed examination of gallstone constituents, fluorescence microscopy [13], X-ray diffraction [14-17], thermogravimetry (TG) and difference scanning calorimetry (DSC) [18], specular reflection spectroscopy [19], scanning electron microscopy (SEM), energy-dispersive X-ray spectroscopy (EDX), and

(C) The Author(s). 2018 Open Access This article is distributed under the terms of the Creative Commons Attribution 4.0 International License (http://creativecommons.org/licenses/by/4.0/), which permits unrestricted use, distribution, and 
Nuclear Magnetic Resonance (NMR) have been applied for selected samples [20].

FT-IR has contributed greatly to our understanding of gallstone composition and is the major tool of choice for classification of gallstones. Nevertheless, together with visual inspection, gallstone classification using FT-IR is far from being unambiguous, as most gallstones are a mixture of several chemical substances and the absorption bands of chemical species often overlap. In this paper, we report the results of classification of 26 gallstones by FT-IR and photography, and address the ambiguity issues of gallstone classification.

\section{Methods}

Twenty-six gallstones, collected from gallbladders after cholecystectomy, were provided by the department of internal medicine at Eulji University Hospital without any patient information. After washing with deionized water, the gallstones were dried under vacuum for $12 \mathrm{~h}$. Once the drying process was completed, a digital photograph was taken of each gallstone. The gallstone was halved by a scalpel for a digital photograph of the internal morphology. The gallstone was then powdered using an agate mortar and pestle. The powder was diluted with $\mathrm{KBr}$ in a proportion of $1 \%(w / w)$. By using a special dye, the powder was pressed on to a translucent film, which was subsequently used for the analysis by a FT-IR spectrophotometer (FTS 3000, Bio-Rad, Cambridge, MA, USA) at $400-4000 \mathrm{~cm}^{-1}$ with a $4 \mathrm{~cm}^{-1}$ resolution. Each sample was subject to 100 scans and the average spectrum was obtained in the absorbance mode.

The gallstones were classified by comparing the respective absorption peaks with the values reported in the literature, as shown in Table 1. The photographs of gallstones from each group were collected and compared with each other to identify the presence of a common morphology in the same group.

\section{Results}

Twenty-six gallstones were classified into six groups after careful examination of each gallstone's FT-IR spectrum, as shown in Table 2.

\section{Pure cholesterol gallstones}

The FT-IR spectrum of a pure cholesterol gallstone as well as the chemical structure of cholesterol is shown in Fig. 1, wherein y axis unit is absorbance and the axis is removed for display. Table 1 shows the comparison between the FT-IR absorption peaks of cholesterol gallstones in this study and those reported in previous studies. The FT-IR spectrum of a cholesterol gallstone was composed of a $\mathrm{CH}_{2}$ asymmetric stretching absorption band at $2934 \mathrm{~cm}^{-1}$, a $\mathrm{CH}_{2}$ symmetric stretching absorption band at $2860 \mathrm{~cm}^{-1}$, a $\mathrm{CH}_{2}$ asymmetric bending absorption band at $1458 \mathrm{~cm}^{-1}$, a $\mathrm{CH}_{2}$ symmetric bending absorption band at $1373 \mathrm{~cm}^{-1}$, and a C-C stretching absorption band at $1055 \mathrm{~cm}^{-1}$ [10] A broad $\mathrm{OH}$ stretching mode absorption band was centered at $3410 \mathrm{~cm}^{-1}$. The band at $2353 \mathrm{~cm}^{-1}$ was an artifact representing the $\mathrm{CO}_{2}$ absorption by air. There was no other absorption peak observed in this spectrum, indicating that these stones were composed of pure cholesterol. Of the 26 gallstones, nine (34.6\%) belonged to the pure cholesterol gallstone group.

The photographs of pure cholesterol gallstones are collected in Fig. 2, and a green plastic ruler demonstrated the dimensions of the stone. Three stones were multiple and the remaining six were singular. Two were of multinuclear berry type (\#3, \#17). Three stones (\#10, $\# 17$, \#24) were completely yellow inside and out, but the surface of the other six gallstones was covered with either a green or brown layer.

\section{Calcium bilirubinate gallstones}

The FT-IR spectrum of a calcium bilirubinate gallstone, together with chemical structure of calcium bilirubinate is shown in Fig. 3, wherein y axis unit is absorbance and the axis is removed for display. The spectrum matched well with the FT-IR spectrum of pure calcium bilirubinate reported by Suo et al. [19]. The spectrum had characteristic doublet absorption peaks at $3398 \mathrm{~cm}^{-1}$ and $3264 \mathrm{~cm}^{-1}$ as well as triplet peaks at 1663, 1624, and $1566 \mathrm{~cm}^{-1}$. One of the doublet absorption peaks at $3398 \mathrm{~cm}^{-1}$ is sharp, and the band at $3264 \mathrm{~cm}^{-1}$ was broad and it appeared that the latter overlapped with a broad absorption band at $3600-2400 \mathrm{~cm}^{-1}$. The sharp

Table 1 Characteristic FT-IR absorption bands of 3 major gallstone constituents, $\mathrm{cm}^{-1}$

\begin{tabular}{|c|c|c|c|c|c|}
\hline & Laloum et al. [12] & Kleiner et al. [13] & Gang et al. [19] & Suo et al. [18] & Our study \\
\hline Cholesterol & $1467,1378,1058$ & $\begin{array}{l}3398,2933,2866 \\
1463,1376,1056\end{array}$ & $\begin{array}{l}3408,2934,2867 \\
1446,1367,1057\end{array}$ & $\begin{array}{l}3395,2930,2867 \\
1464,1374,1056\end{array}$ & $\begin{array}{l}3410,2934,2853 \\
1458,1373,1055\end{array}$ \\
\hline $\begin{array}{l}\text { Calcium } \\
\text { bilirubinate }\end{array}$ & $\begin{array}{l}1666,1628 \\
1571,1251\end{array}$ & $1661,1640,1575$ & $\begin{array}{l}3402,1696,1663, \\
1620,1572,1448, \\
1250,700\end{array}$ & $\begin{array}{l}1700,1662,1628 \\
1574,1460,1253 \\
1054\end{array}$ & $\begin{array}{l}3398,1663,1624 \\
1566,1447,1251 \\
699\end{array}$ \\
\hline $\begin{array}{l}\text { Calcium } \\
\text { carbonate }\end{array}$ & $\begin{array}{l}1480,1419 \\
875,855\end{array}$ & 1464,875 & & $\begin{array}{l}\text { broad band at } \\
1300-1500 \text {, } \\
875,711\end{array}$ & $\begin{array}{l}1464,1458, \\
1420 \\
872,855\end{array}$ \\
\hline
\end{tabular}


Table 2 Number and percentage of gallstone groups determined by FT-IR ${ }^{a}$

\begin{tabular}{|c|c|c|c|c|c|c|c|c|}
\hline & \multicolumn{3}{|c|}{ Cholesterol gallstones } & \multicolumn{5}{|c|}{ Calcium bilirubinate gallstones } \\
\hline & Pure & $+\mathrm{CaCO}_{3}$ & $\begin{array}{l}+\mathrm{CaCO}_{3} \\
+\mathrm{CB}\end{array}$ & Pure & $+\mathrm{CP}$ & + Chol & $+\mathrm{CaCO}_{3}$ & $\begin{array}{l}+\mathrm{Chol} \\
+\mathrm{CPH} \\
\end{array}$ \\
\hline Laloum et al. [14] & $53(41.1)$ & 0 & $6(4.7)$ & $26(20.1)$ & $20(15.5)$ & $5(3.9)$ & $8(6.2)$ & $11(8.5)$ \\
\hline Our study & $9(34.6)$ & $1(3.8)$ & $1(3.8)$ & $12(42.3)$ & 0 & $1(3.8)$ & $2(7.6)$ & 0 \\
\hline
\end{tabular}

${ }^{a} \mathrm{Chol}$ Cholesterol, $\mathrm{CaCO}_{3}$ calcium carbonate, $C B$ Calcium bilirubinate, $C P$ calcium palmitate, $C P H$ Calcium phosphate

absorption peak at $3398 \mathrm{~cm}^{-1}$ was previously assigned as a $\mathrm{N}-\mathrm{H}$ stretching vibration of the pyrrole groups, and the broad absorption band at $3264 \mathrm{~cm}^{-1}$ as the lactam $\mathrm{N}-\mathrm{H}$ stretching vibration [18]. The broad absorption band at $3600-2400 \mathrm{~cm}^{-1}$ was identified as the absorption of bound water, $\mathrm{H}_{2} \mathrm{O}$ in $\mathrm{Ca}(\mathrm{HBR})_{2} \cdot \mathrm{H}_{2} \mathrm{O}$ or $\mathrm{Ca}(\mathrm{Br}) \cdot 2 \mathrm{H}_{2} \mathrm{O}$, where $\mathrm{HBR}$ and $\mathrm{BR}$ stand for monovalent and divalent bilirubinate, respectively [19]. The absorption peak at $3398 \mathrm{~cm}^{-1}$ was clearly separated from the band at $3264 \mathrm{~cm}^{-1}$ for six out of the 12 gallstones, owing to the broad absorption band of bound water. The absorption band at $3264 \mathrm{~cm}^{-1}$ appeared as a shoulder of the absorption peak at $3398 \mathrm{~cm}^{-1}$ for five other gallstones. With respect to triplet absorption peaks, 1663 and $1624 \mathrm{~cm}^{-1}$ peaks were observed for bilirubin, and the $1566 \mathrm{~cm}^{-1}$ band was observed only when the carboxylic acid of bilirubin is conjugated with a metal ion such as calcium, forming calcium bilirubinate [8]. In addition, a shoulder peak observed at $1703 \mathrm{~cm}^{-1}$ was assigned to the vibration of a non-conjugated carboxylic acid $[12,19]$. The presence of the absorption peak at $1703 \mathrm{~cm}^{-1}$ indicated that some carboxylic acid groups in the gallstone are monovalent, i.e., calcium bilirubinate in the gallstone includes both $\mathrm{Ca}(\mathrm{HBR})_{2} \cdot \mathrm{H}_{2} \mathrm{O}$ and $\mathrm{Ca}(\mathrm{Br})$ $.2 \mathrm{H}_{2} \mathrm{O}$ forms. The absorption bands at $1447 \mathrm{~cm}^{-1}$ were assigned to the pyrrole ring deformation and were observed for both bilirubin and calcium bilirubinate. Furthermore, the absorption peak at $1251 \mathrm{~cm}^{-1}$ was previously assigned for amino $\mathrm{C}-\mathrm{N} /$ carboxylate $\mathrm{C}-\mathrm{O}$ stretching, and at $699 \mathrm{~cm}^{-1}$ for the lactam ring deformation. FT-IR spectrum of pure calcium bilirubinate, reported by Suo et al., had a doublet absorption band at above $3000 \mathrm{~cm}^{-1}$ and triplet absorption peaks between 1500 and $1700 \mathrm{~cm}^{-1}$, without the broad absorption band of bound water at $3600-2400 \mathrm{~cm}^{-1}$.

The photographs of the gallstones belonging to the calcium bilirubinate gallstone group are shown in Fig. 4. Twelve out of the 26 gallstones belonged to this group (46.0\%). Calcium bilirubinate gallstones were predominantly black, but gallstone \#14 had some yellow-colored substance. The FT-IR spectrum did not show the characteristic absorption peaks of cholesterol $\left(\mathrm{CaCO}_{3}\right.$ or $\left.\mathrm{Ca}_{3} \mathrm{PO}_{4}\right)$, and hence, we suspected that the yellow substance was a chemical species with a small absorption coefficient.

\section{Cholesterol gallstones mixed with calcium carbonate or calcium bilirubinate}

The FT-IR spectra of cholesterol stones mixed with calcium carbonate or calcium bilirubinate are collected and displayed in Fig. 5, wherein y axis unit is absorbance and. The y axis was offset and removed for display and comparison. The FT-IR spectrum of calcium carbonate is known to have a broad absorption peak at 1420$1480 \mathrm{~cm}^{-1}$, as well as sharp absorption peaks at 872 and $855 \mathrm{~cm}^{-1}[14,15]$. The FT-IR spectrum of a cholesterol stone mixed with calcium carbonate consisted of the characteristic absorption bands of cholesterol at 3410, 2933, and $1055 \mathrm{~cm}^{-1}$. However, the asymmetric bending

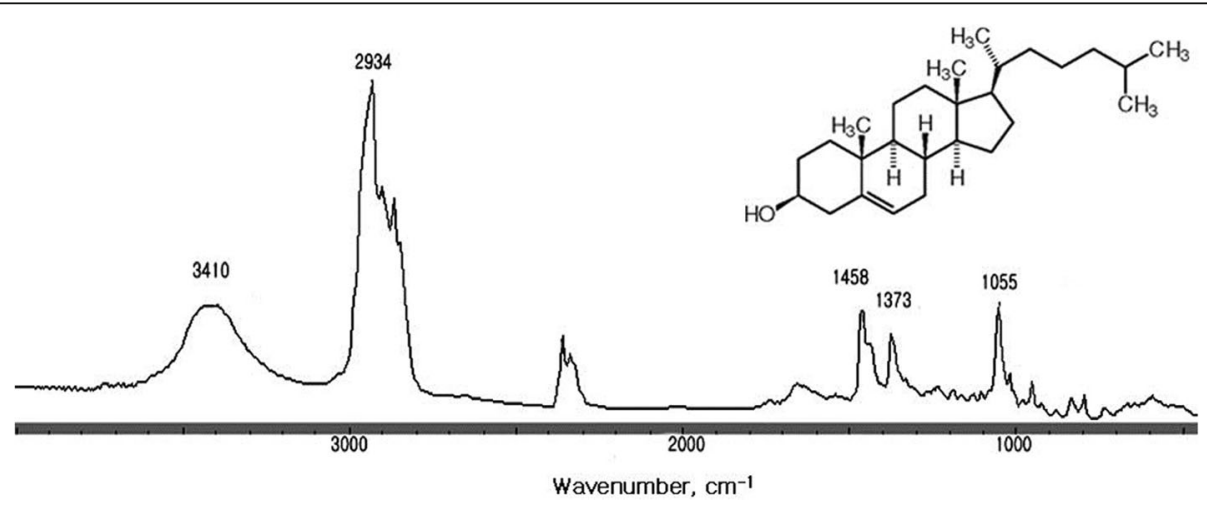

Fig. 1 Chemical structure of cholesterol and typical Fourier-transform infrared (FT-IR) spectrum of a pure cholesterol gallstone. The broad absorption band of cholesterol $\mathrm{OH}$ group is centered at $3410 \mathrm{~cm}^{-1}$ 


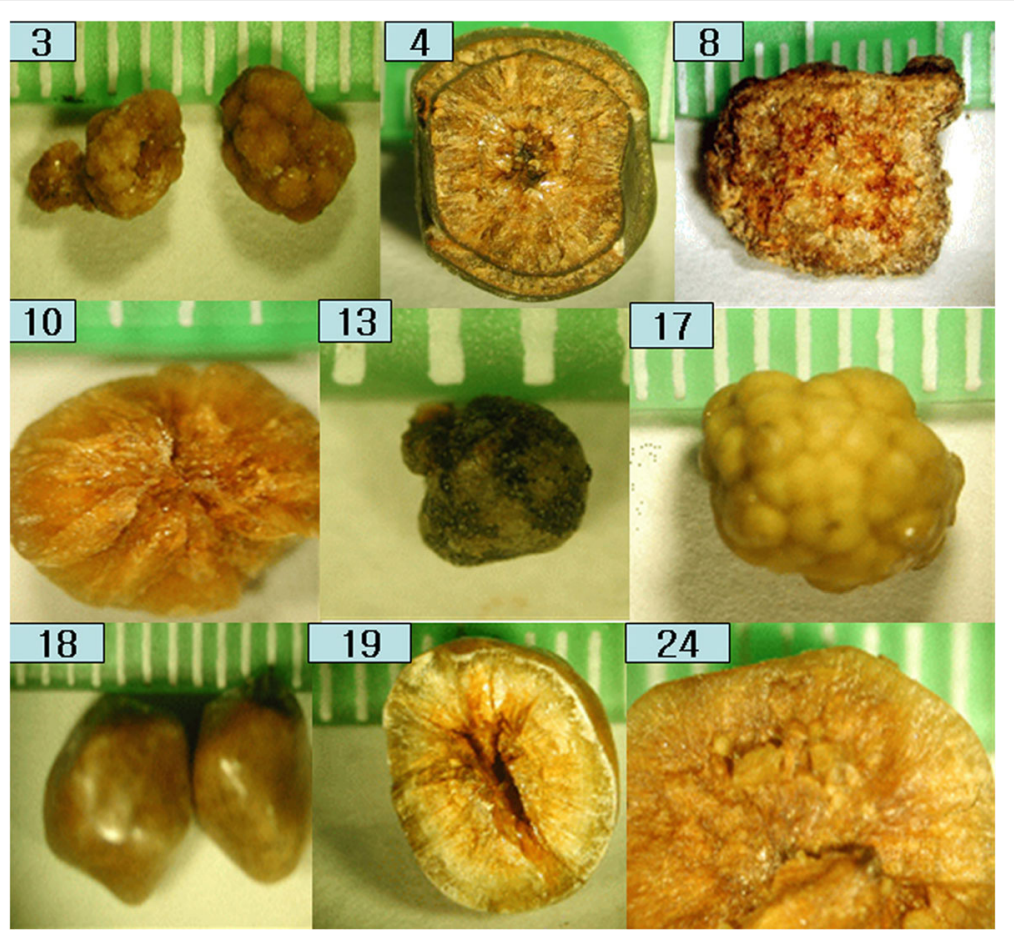

Fig. 2 Photographs of pure cholesterol gallstones. Three stones $(\# 10, \# 17, \# 24)$ are completely yellow inside and out, but the other 6 gallstones are covered with a green or brown layer

mode absorption peak of cholesterol $\mathrm{CH}_{2}$ at $1458 \mathrm{~cm}^{-1}$ was superimposed on the broad absorption band of $\mathrm{CO}_{3}{ }^{2-}$ ion and the resultant peak had a higher intensity than that of the pure cholesterol gallstone, as shown in Fig. 1. The $\mathrm{CH}_{2}$ symmetric bending mode peak of cholesterol at $1373 \mathrm{~cm}^{-1}$ appeared as a shoulder of the carbonate absorption band at $1464 \mathrm{~cm}^{-1}$. In addition, the characteristic absorption peak of carbonate at 872 and $855 \mathrm{~cm}^{-1}$ was observed for cholesterol gallstones mixed with calcium carbonate. Only one gallstone belongs to this group (3.8\%), with a morphology similar to that of a pure cholesterol gallstone, but the cut surface was neither radial nor concentric; it was irregular and glossy (\#23 in Fig. 6).
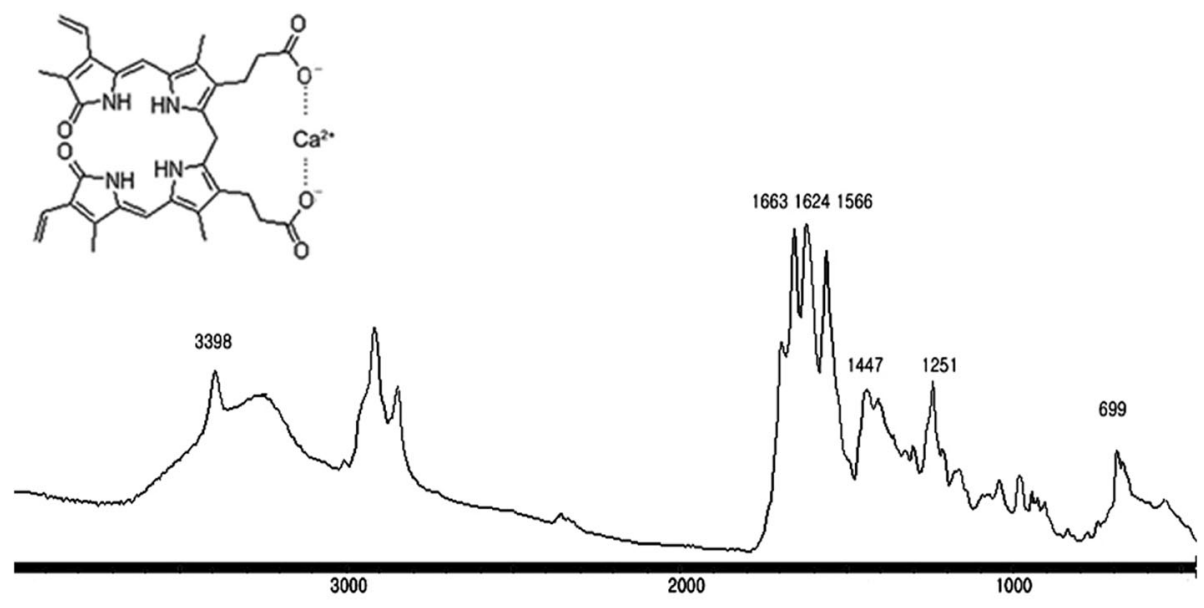

Wavenumber, $\mathrm{cm}^{-1}$

Fig. 3 Chemical structure of calcium bilirubinate and Fourier-transform infrared (FT-IR) spectrum of a calcium bilirubinate gallstone. The spectrum has a characteristic triplet absorption peak centered at around $1624 \mathrm{~cm}^{-1}$ and a pyrrole N-H absorption peak at $3398 \mathrm{~cm}^{-1}$ 


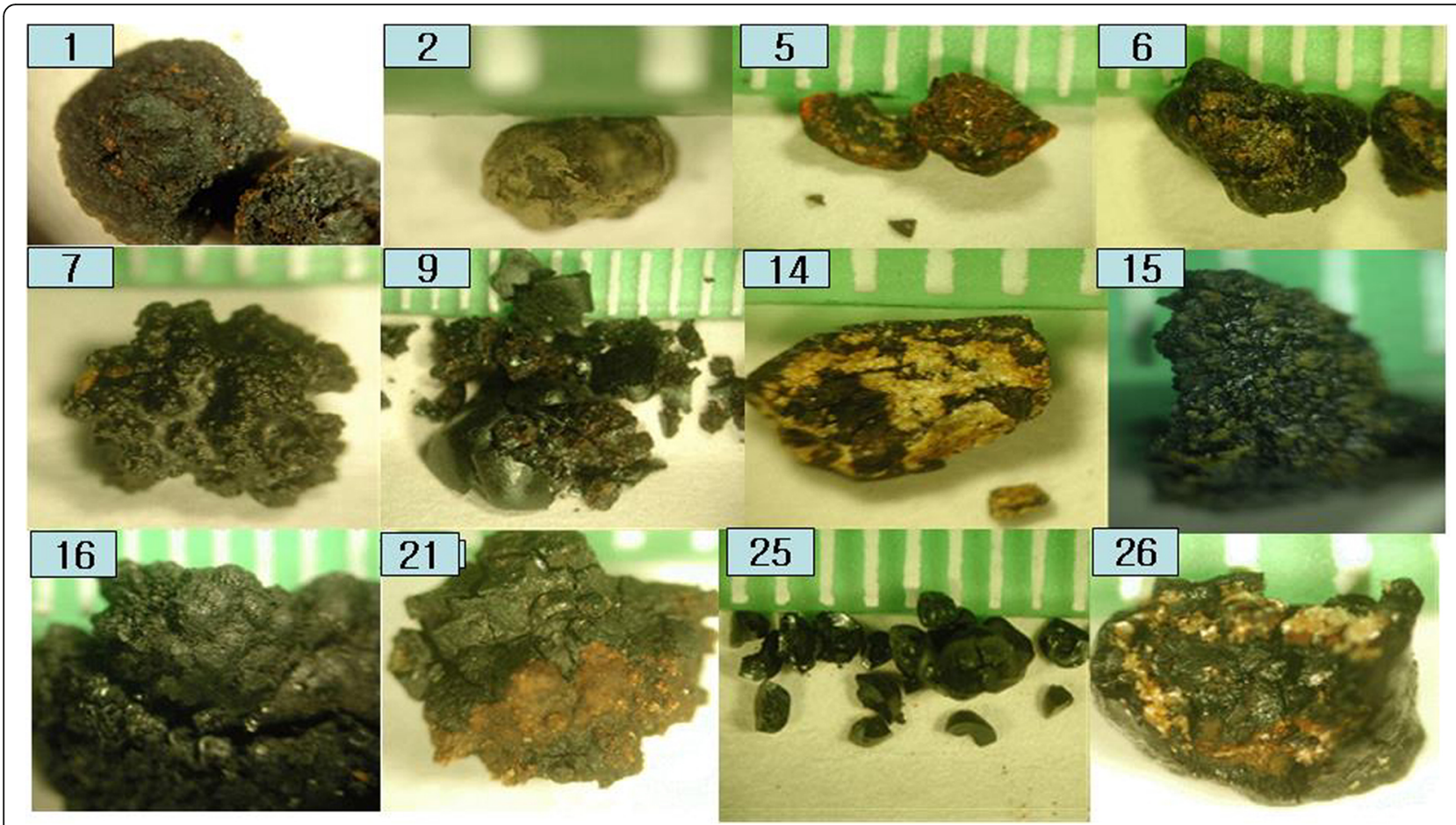

Fig. 4 Photographs of calcium bilirubinate gallstones. The gallstones are mostly black but some include a reddish yellow substance

The FT-IR spectrum of a cholesterol gallstone mixed with calcium bilirubinate together with calcium carbonate, shown in Fig. 7, had a typical triplet absorption band of a calcium bilirubinate centered at $1624 \mathrm{~cm}^{-1}$ as well as a typical calcium carbonate broad absorption band centered at $1458 \mathrm{~cm}^{-1}$. The absorption band at $3410 \mathrm{~cm}^{-1}$ shifts to $3398 \mathrm{~cm}^{-1}$ as the cholesterol $\mathrm{OH}$ absorption band overlapped with the pyrrole absorption band of calcium bilirubinate. The absorption bands at 1458,872 , and $855 \mathrm{~cm}^{-1}$ were indications of the presence of a carbonate $\mathrm{CO}_{3}{ }^{2-}$. Only one gallstone belonged to this

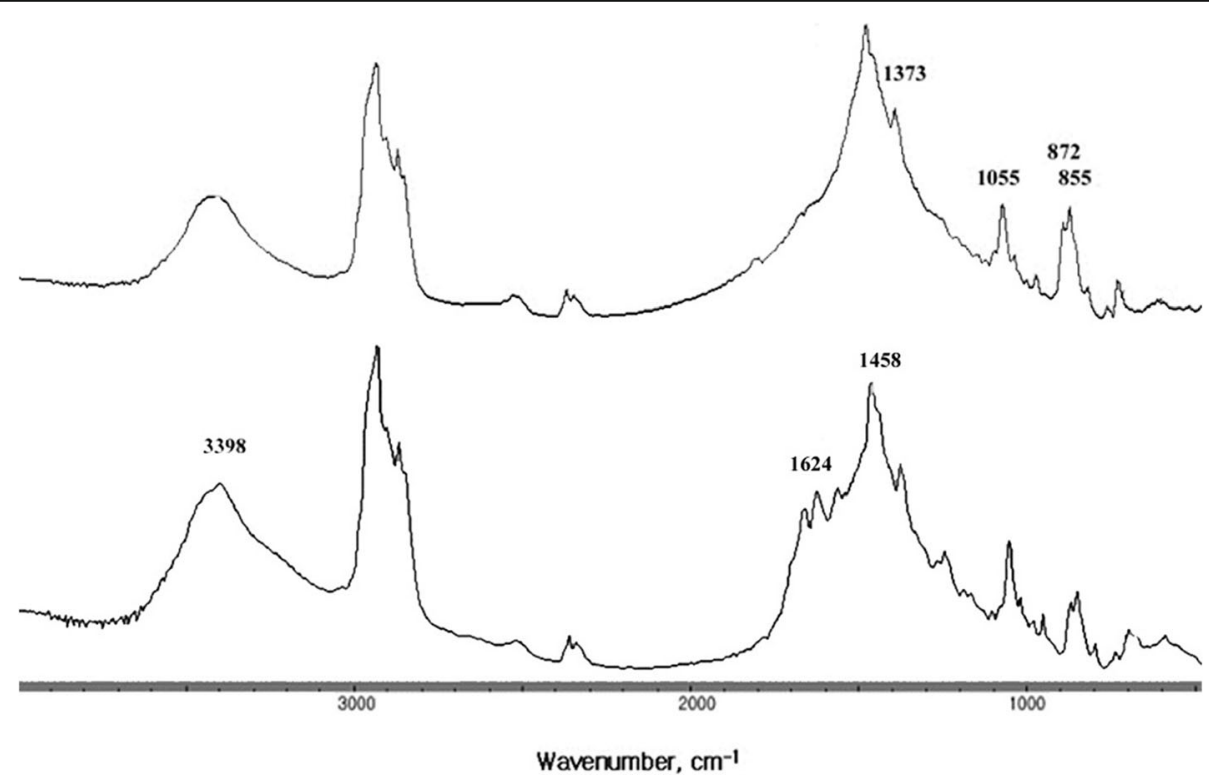

Fig. 5 Fourier-transform infrared (FT-IR) spectra of a cholesterol gallstone mixed with calcium carbonate (top) and a cholesterol gallstone mixed with both calcium carbonate and calcium bilirubinate (bottom). The presence of calcium carbonate is indicated by the absorption peaks at 1458,872 , and $855 \mathrm{~cm}^{-1}$, and calcium bilirubinate by a triplet absorption peak centered at $1624 \mathrm{~cm}^{-1}$ and a pyrrole N-H absorption peak at $3398 \mathrm{~cm}^{-1}$ 


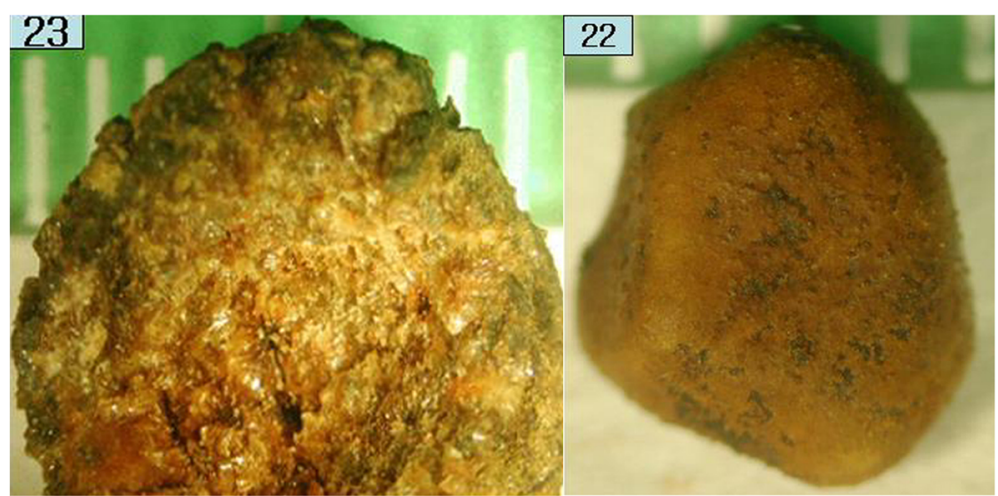

Fig. 6 Photographs of a cholesterol gallstone mixed with calcium carbonate (\#23) and a cholesterol gallstone mixed with both calcium carbonate and calcium bilirubinate (\#22)

group (3.8\%). This gallstone appears as a multi-faceted brown color stone (\#22 in Fig. 6).

\section{Calcium bilirubinate gallstone mixed with cholesterol} As shown in Fig. 7, the FT-IR spectrum of a calcium bilirubinate gallstone mixed with cholesterol had all the characteristic absorption peaks of calcium bilirubinate (3398, 2919, 1663, 1624, 1566, 1251, and $699 \mathrm{~cm}^{-1}$ ). In addition, it had a characteristic cholesterol absorption peak at $1055 \mathrm{~cm}^{-1}$. One gallstone belonged to this group (3.8\%). This gallstone had a radial and concentric morphology and was brown in color (\#12 in Fig. 8).

Calcium bilirubinate gallstone mixed with calcium carbonate The FT-IR spectrum of a calcium bilirubinate gallstone mixed with calcium carbonate is shown in Fig. 7, wherein y axis unit is absorbance. The y axis was offset and removed for display and comparison. The spectrum had all the characteristic calcium bilirubinate absorption bands as well as characteristic calcium carbonate (calcite) absorption peaks at 1464, $855 \mathrm{~cm}-1$. These gallstones were brownish in color and contained scattered inorganic particles inside and out (\#11 and \#20 in Fig. 8). Two gallstones belonged to this group (7.7\%).

\section{Discussion}

We studied the FT-IR spectra and photographic images of 26 gallstones and classified them into six categories based upon the FT-IR absorption characteristics. Institutional review for gallstone collection was not necessary, as the gallstones were the remnants of cholecystectomy
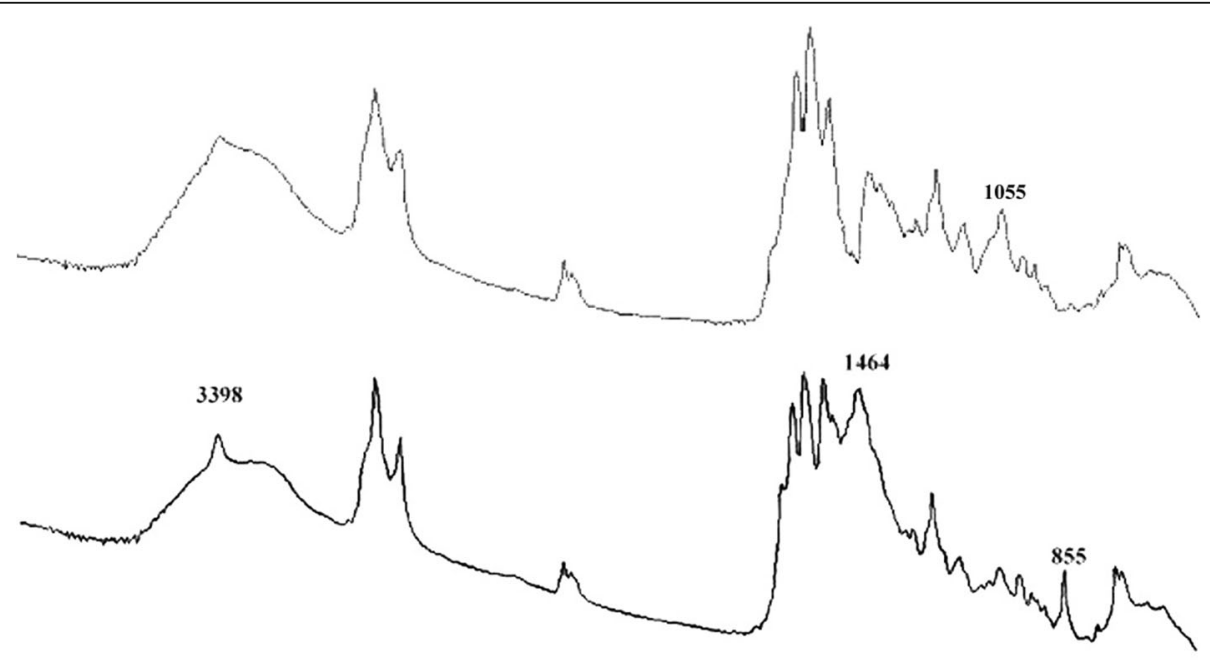

3000

Fig. 7 Fourier-transform infrared (FT-IR) spectra of calcium bilirubinate gallstone mixed with cholesterol (top) and a calcium bilirubinate gallstone mixed with calcium carbonate (bottom) 


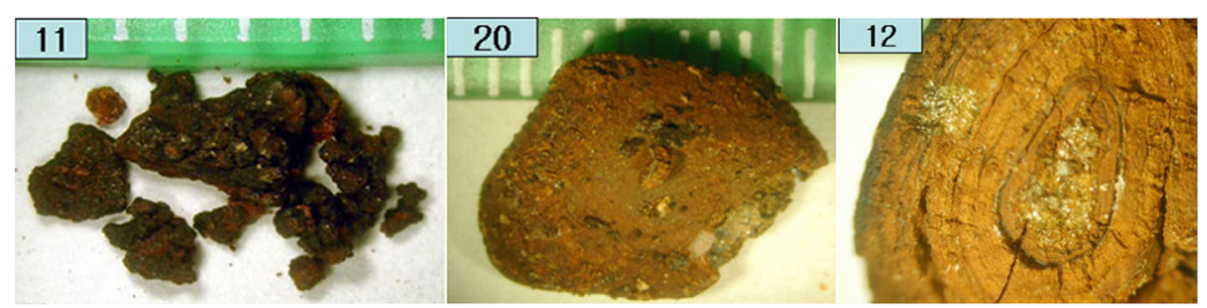

Fig. 8 Photographs of calcium bilirubinate gallstones mixed with calcium carbonate (\#11, \#20) and a calcium bilirubinate gallstone mixed with cholesterol (\#12)

(resection of gallbladder for treatment of acute cholecystitis). According to Article 33 of the Enforcement Rule of Bioethics and Safety Act by the Korean government, institutional review can be exempt for this type of research as long as patient information is withheld.

Characteristic absorption bands of the three major components of the gallstones, namely cholesterol, calcium bilirubinate, and calcium carbonate, corresponded to the reported values well within the ranges of experimental error, as shown in Table 1. All the pure cholesterol gallstones showed a consistent FT-IR spectrum and gallstones with a very distinct green or brown surface color did not show any significant FT-IR absorption band other than that of cholesterol. This indicates that the green or brown surface layer was very thin, as can be confirmed from the photographs in Fig. 1.

The highest number of gallstones, eleven out of a total of twenty-six (46.0\%), belonged to the calcium bilirubinate group, although they are black in most cases, some have red or yellow particles scattered inside and out. However, there were no significant FT-IR absorption bands indicating cholesterol, calcium carbonate, or calcium phosphate. This could be due to a drawback of FT-IR technique: FT-IR absorption is not sensitive to minor chemical species, particularly when the minor component has a smaller extinction coefficient than the major component. Other analytical techniques should have been applied for identification of these particles, but we mistakenly powdered the whole gallstone for preparing the FT-IR sample. We learned a valuable lesson that a part of the gallstone should be saved for further analysis, especially if the gallstone has a visually apparent second component.

Calcium carbonate in a gallstone is easy to identify using FT-IR spectroscopy as the characteristic absorption bands at 855 and $872 \mathrm{~cm}^{-1}$ do not interfere with the absorption bands of cholesterol or calcium bilirubinate. Calcium carbonate can be found together with cholesterol, calcium bilirubinate, or both calcium bilirubinate and cholesterol, and the color of these gallstones are light to dark brown in all cases, as can be seen in Figs. 6 and 8.

Gallstones have traditionally been classified as cholesterol, black pigment, brown, and mixed, based primarily on external color and morphology [1-3]. It should be noted, however, that a pure cholesterol gallstone could occasionally be misjudged as a brown gallstone due to a very thin brown-colored layer covering the stone, as seen in Fig. 2. Most black gallstones were revealed to be calcium bilirubinate gallstones. Brown gallstones should be classified with care, as they could be a cholesterol gallstone covered with a very thin brown layer (Fig. 2), a mixed gallstone of cholesterol with calcium bilirubinate and calcium carbonate (Fig. 6), or a mixed gallstone of calcium bilirubinate with calcium carbonate (Fig. 8).

A side-by-side comparison of the FT-IR spectrum of a gallstone with its corresponding photographic image was attempted previously for selected gallstone samples, and it helped to understand the chemical composition and morphology of those gallstones. To our knowledge, however, this study is the first attempt to compare and classify gallstones using the FT-IR spectra and photographic images of the whole gallstone samples in a gallstone classification study.

\section{Conclusion}

FT-IR has been tool of choice for classifying a large number of gallstone samples. However, this study demonstrated that care must be taken for classifying the gallstones using FT-IR alone as the absorption bands of gallstone constituents often overlap with each other and the absorption of bound water makes the interpretation of FT-IR spectrum of calcium bilirubinate gallstones difficult. Interpretation of the FT-IR spectrum of a gallstone should be given due attention, and further research using various analytical techniques is warranted for understanding the constituents of gallstones and the etiology of gallstone formation.

\section{Abbreviation}

FT-IR: Fourier-transform infrared

Funding

This study was supported in part by 2018 Eulji university research grant.

Availability of data and materials

For data requests, please contact the authors. 


\section{Authors' contributions}

BJH prepared the samples for FT-IR study and analyzed the spectra. SP designed and coordinated the research. Both authors read and approved the final manuscript.

\section{Ethics approval and consent to participate} Not applicable.

\section{Consent for publication}

All authors have consented to the submission of this manuscript for publication.

\section{Competing interests}

The authors declare that they have no competing interests.

\section{Publisher's Note}

Springer Nature remains neutral with regard to jurisdictional claims in published maps and institutional affiliations.

\section{Author details}

'Department of Beauty and Cosmetics, College of Health Science, Eulji University, Seongnam, Gyeonggi-do 13135, South Korea. ${ }^{2}$ Department of Biomedical Engineering, College of Health Science, Eulji University, 553 Sanseongdae-ro, Sujeong-gu, Seongnam, Gyeonggi-do 13135, Republic of Korea.

Received: 26 April 2018 Accepted: 27 June 2018

Published online: 18 July 2018

\section{References}

1. Grunhage F, Lammert F. Gallstone disease pathogenesis of gallstones: a genetic perspective. Best Pract Res Clin Gastroenterol. 2006;20(6):997-1015.

2. Carey MC. Pathogenesis of gallstones. Am J Surg. 1993;165:410-9.

3. Maki T, Marsushiro T, Suzuki N. Clarification of the nomenclature of pigment gallstones. Am J Surg. 1982;144:302-5.

4. Liu X, Hu J. Relationship between bilirubin free radical and formation of pigment gallstone. World J Gastroenterol. 2002:8(3):413-7.

5. Shareef KM, Omer LA, Garota SA. Predicting the chemical composition of gallstones by FTIR spectroscopy. Biomed Pharmacol J. 2008;1(1):25-30.

6. Yoo EH, Oh HJ, Lee SY. Gallstone analysis using fourier transform infrared spectroscopy (FT-IR). Clin Chem Lab Med. 2008;46(3):376-81.

7. Schafmayer C, Hartleb J, Tepel J, et al. Predictors of gallstone composition in 1025 symptomatic gallstones from northern Germany. BMC Gastroenterol. 2006:6(36):1-9. https://doi.org/10.1186/1471-230X-6-36.

8. Sikkandar S, Jayakumar S, Gunasekaran S. Study on the analysis of human gallstones using fourier transform infrared spectroscopic technique. Int J ChemTech Res. 2011;3(1):149-54.

9. Stringer MD, Taylor DR, Soloway RD. Gallstone composition: are children different? J Pediatr. 2003;142(4):435-40.

10. Trotman BW, Morris TA, Sanchez HM, et al. Pigment vs. cholesterol cholelithiasis: identification and quantification by infrared spectroscopy. Gastroenterol. 1977;72:495-6.

11. Malet PF, Dabezies MA, Huang G, et al. Quantitative infrared spectroscopy of common bile duct gallstones. Gastroenterol. 1988;94(5):1217-21.

12. Laloum E, Dao NQ, Daudon M. Cluster analysis of gallstone FT-IR spectra: tests on simulated mixture spectra and comparison between spectral and morphological classification of human gallstones. Appl Spectrosc. 1998;52: 1210-21.

13. Kleiner $\mathrm{O}$, Ramesh J, Huleihel $\mathrm{M}$, et al. A comparative study of gallstones from children and adults using FTIR spectroscopy and fluorescence microscopy. BMC Gastroenterol. 2002;2:3-11.

14. Wosiewitz U, Schroebler S. On the chemistry of 'black' pigment stones from the gallbladder. Clinica. Chim Acta. 1978;89:1-12.

15. Bassi N, Del Favero G, Meggiato T, et al. Are morphology and composition of gallstones related? An x-ray-diffraction study. Curr Ther Res. 1994;55(10): 1169-75.

16. Palchik NA, Moroz TN. Polymorph modifications of calcium carbonate in gallstones. J Cryst Growth. 2005;283:450

17. Ramya RJ, Arul KT, Epple M, et al. Chemical and structural analysis of gallstones from the Indian subcontinent. Mater Sci Eng C Mater Biol Appl. 2017;78:878-85
18. Toscano RA, Melo DMDA, de Moura MDF, et al. TG and DSC investigation of gallstone samples collected from patients submitted to cholecystectomy. Thermochim Acta. 2004;410(1-2):125-31.

19. Suo $T$, Peng $P$, Feng $M$, et al. Fixed-point and stratified analysis of the fine structure and composition of five gallstones with fourier transform infrared (FT-IR) specular reflection spectroscopy. Microsc Res Tech. 2012;75(3):294-9. https://doi.org/10.1002/jemt.21057.10.1016/j.msec.2017.04.004.

20. Gang L, Xing D, Wang H, et al. Vibrational spectroscopic study of human pigment gallstones and their insoluble materials. J Mol Struct. 2002;616:187-91.

\section{Ready to submit your research? Choose BMC and benefit from:}

- fast, convenient online submission

- thorough peer review by experienced researchers in your field

- rapid publication on acceptance

- support for research data, including large and complex data types

- gold Open Access which fosters wider collaboration and increased citations

- maximum visibility for your research: over $100 \mathrm{M}$ website views per year

At BMC, research is always in progress.

Learn more biomedcentral.com/submissions 